\title{
RESEÑA DE SENTENCIAS DEL TRIBUNAL CONSTITUCIONAL.
}

\section{SENTENCIAS QUE APARECEN PUBLICADAS EN LOS BOLETINES OFICIALES DEL ESTADO DURANTE EL TERCER TRIMESTRE DE 1990.}

\author{
POR \\ Francisco Javier Fernandez Gonzalez.
}

Seminario de Derecho Administrativo. Universidad de Oviedo.

( (B.O.E." de 5 de enero de 1990. Suplemento al no 160)

SENT.№ 102/1990, DE 4 DE JUNIO. SALA SEGUNDA.

RECURSO DE AMPARO № 524/1988.

OBJETO: Promovido contra el Auto de la Sala Cuarta del Tribunal Supremo de 3 de marzo de 1988 desestimando recurso de súplica del acto. La cuestión suscitada es la consistente en dilucidar si ha existido indefensión o no del acto en el recurso contencioso-administrativo planteado por el Ayuntamiento de San Fernando contra la Sentencia previa dictada por la Sala de lo Contencioso-Administrativo de la Audiencia Territorial de Sevilla, que declaró no ajustados a Derecho determinados actos del citado Ayuntamiento referentes a la concesión de una licencia para relleno de terrenos. Lo que se denuncia es la existencia de un error por parte del órgano judicial consistente en no haber proveído el escrito de personación del actor presentado en su condición de apelado dentro del plazo legalmente previsto al efecto.

FALLO: Otorgar el amparo solicitado, ya que como consecuencia del error señalado en la tramitación del recurso de apelación, el recurrente no ha sido oído en el mismo, sin poder ejercer así la defensa de sus pretensiones; $y$, en su virtud:

$1^{\text {a }}$ Reconocer su derecho a la tutela judicial efectiva sin indefensión.

$2^{\circ}$ Declarar nula la Sentencia de la Sala Cuarta del Tribunal Supremo, de 5 de Junio de 1987, y todas las resoluciones posteriores dictadas en el recurso de apelación 2560/1985.

$3^{\circ}$ Retrotraer las actuaciones al momento en que por el recurrente se presentó escrito de personación en el citado recurso, pa- 
ra que la Sala correspondiente del Tribunal Supremo provea al mismo y, tras los oportunos trámites, dicte nueva Sentencia.

SENT.N№ 105/1990, DE 6 DE JUNIO. SALA PRIMERA.

RECURSO DE AMPARO № 1695/1987. LUIS LOPEZ GUERRA.

OBJETO: Interpuesto contra Sentencia de 25 de noviembre de 1987 de la Audiencia Provincial de Zaragoza por la que se condena a un periodista deportivo por un delito de desacato a las Cortes de Aragón y a un Diputado de las mismas. Mantiene el recurrente que tal condena viene a suponer, por un lado, la vulneración del derecho reconocido en el art. 20.1.d.) de la Constitución a comunicar libremente información veraz por cualquier medio de difusión, así como el reconocido en el art. 24.1 de la CE, a la tutela judicial efectiva. Ambas vulneraciones se reconducen a la de que el Tribunal sentenciador no estimó que la conducta sancionada respondía al uso y ejercicio legítimo de un derecho constitucionalmente reconocido, como es el de informar verazmente.

FALLO: Denegar el amparo solicitado, puesto que si bien parte de las manifestaciones realizadas en el programa radiofónico de que se trata constituyeron, por un lado, una información debidamente contrastada sobre una conducta de interés público, $y$, por otro, una evaluación o crítica -fuertemente negativa- de esa conducta, otra parte de ellas se configuran como efectivamente desvinculadas de todo propósito informativo, o, evaluativo de conductas de relevancia pública, por lo que cabe apreciar que el recurrente, en este último aspecto, no actuó dentro del ámbito protegido por el art. 20.1 de la CE.

SENT. № 106/1990, DE 6 DE JUNIO. PLENO.

CUESTIONES DE INCONSTITUCIONALIDAD 1976, 2176, 2442, 2491,2492, 2535 Y 2593/1989 Y 251 Y 439/1990. EUGENIO DIAZ EIMIL.

OBJETO: Planteadas por la sala de lo Contencioso Administrativo del Tribunal Superior de Justicia de Canarias, por supuesta inconstitucionalidad de los arts. 2, 4, Disposición adicional y Disposiciones transitorias de la Ley del Parlamento de Canarias 5/21989, de 4 de mayo, de Reorganización Universitaria de Canarias, por supuesta infracción del artículo 27.10 de la Constitución. 
MATERIAS: Posible incompatibilidad con la autonomía universitaria (27.10 CE) de algunos preceptos de la Ley Canaria.

\section{1) Consideraciones generales.}

- La idea motriz de la reforma, es, fundamentalmente, la regla general de que los centros de la Universidad de la Laguna no se localicen en Gran Canaria, ni los de la Universidad de las Palmas lo hagan en Tenerife.

- Sin perjuicio de ese criterio de territorialización que ordenará en el futuro la creación de nuevos centros universitarios, la Ley aborda la readscripción de los existentes que no se adecúan al mismo, disponiendo, a tal efecto, que los centros de la Universidad de la Laguna situados en Gran Canaria queden integrados en la Universidad de Las Palmas y los dependientes de ésta situados en Tenerife pasen a la Universidad de La Laguna.

- El juicio sobre la adecuación de la Ley canaria 5/1989 al derecho fundamental y garantía institucional de autonomía universitaria, necesariamente habrá de tomar como punto de referencia las previsiones de la L.R.U. relativas a las competencias atribuidas a las Universidades en orden a garantizar su autonomía, por cuanto que esas previsiones son las que han dotado de contenido positivo a la misma.

\section{2) Readscripción de los actuales centros.}

- El art. 2 y las Disposiciones adicional y transitoria de la Ley canaria 5/1989 disponen la readscripción de los actuales centros y demás estructuras básicas e las Universidades canarias; y en este sentido el art. 2 establece que tanto la Universidad de la Laguna como la de las Palmas de Gran Canaria, contarán inicialmente con los centros y demás estructuras básicas que tengan su ubicación física respectiva en las islas de Tenerife y de Gran Canaria, independientemente de su origen y actual adscripción. Se produce de este modo una readscripción de Centros y estructuras básicas que supone, para cada una de las Universidades, la pérdida de unos y la asunción de otros en función de su previa localización territorial. - A juicio del TC esta medida no vulnera la autonomía universitaria puesto que:

a) La autonomía universitaria no incluye el derecho de las Universidades a contar con unos u otros concretos centros, imposibilitando o condicionando así las decisiones que al Estado o a las Comunidades Autónomas corresponde adoptar en orden a la determinación y organización del sistema universita- 
rio, pues dicha autonomía se proyecta internamente, y ello aun con ciertos límites, en la autoorganización de los medios de que dispongan las Universidades para cumplir y desarrollar las funciones que, al servicio de la sociedad, les han sido asignadas.

b) La pérdida de Profesores que se produce por la segregación de los centros en los que prestan sus servicios y su correlativa incorporación a otra Universidad no es, en si misma considerada, lesiva de la autonomía universitaria.

c) Tampoco desde la consideración de la autonomía económica y financiera de las Universidades cabe formular objeción de inconstitucionalidad a la readscripción de centros prevista en la Ley canaria.En palabras del TC, se produce "una mutación demanial por cambio de la competencia sobre la gestión de determinados centros que siguen integrados en el servicio público universitario, mutación que no puede estimarse lesiva de la autonomía universitaria en su manifestación económica y financiera, por cuanto que ésta no es ajena, ni independiente, de las competencias y servicios concretos encomendados a la Universidad, pues la titularidad de los bienes encuentra su justificación en la prestación del servicio público universitario, de manera que, reestructurándose la gestión de determinados centros y encomendándose la misma a una u otra Universidad, es evidente que los bienes afectados a cada centro en concreto deben ser adscritos a la titularidad demanial de la Universidad que asuma sobre ellos competencia. Por lo tanto, a diferencia de los supuestos de supresión de centros que conlleva la desafectación de sus bienes, la singularidad del supuesto contemplado en la Ley canaria, en el que se mantienen los centros readscritos, no se produce cesación del servicio público que vienen prestando y ello explica que se produzca cambio de titularidad de sus bienes, sin que sea precisa la concurrencia del consentimiento de quien, por decisión del legislador competente, deja de tener asignada la gestión del centro y sin que, con mayor razón, ese cambio de titularidad requiera el ejercicio de la potestad expropiatoria ni, en su consecuencia, se produzca infracción de los atrs. 31 y 33 de la CE, puesto que la titularidad de los bienes está en función de la competencia para gestionarlos".

- La readscripción de centros no interfiere las facultades que la L.R.U. asigna a las Universidades en orden al "establecimiento y modificación de sus plantillas", "selección, formación y promoción del personal docente e investigador" y "elaboración de planes de 
estudio e investigación", puesto que el ejercicio concreto de tales facultades está en relación directa con los medios personales y materiales de que previamente dispongan las Universidades, y la determinación de esos medios resulta ajena a las mismas por ser decisión que sólo corresponde adoptar al Estado o a las Comunidades Autónomas. Las dos Universidades implicadas pueden ejercitar las citadas facultades de acuerdo con los medios personales $y$ materiales de que dispongan después de llevarse a cabo su ordenación.

- Respecto a la potestad que la L.R.U. reconoce a las Universidades para la "creación de estructuras específicas que actúen como soporte de la investigación y de la docencia", el TC entiende que no ha sido quebrantada puesto que 'de un lado, el art. 2 no crea estructura universitaria alguna...., sino que se limita a redistribuir las ya existentes de acuerdo con el criterio territorial que inspira la Ley de Reorganización Universitaria de Canarias y, de otro lado, la citada potestad organizativa de las Universidades comprende únicamente las estructuras que la propia L.R.U. no considera básicas, quedando, por lo tanto, fuera de su ámbito, la creación de estructuras organizativas básicas, que son, precisamente, a las que se refiere exclusivamente dicho art. 2, no para crearlas, sino para redistribuirlas".

3) Creación de nuevos centros en las reordenadas Universidades Canarias.

- La Sala proponente de las Cuestiones de inconstitucionalidad sostiene que el articulo 4 de la Ley canaria impugnada (el cual establece normas que tienen por objeto regular la creación de nuevos centros en las reordenadas Universidades Canarias), consagra una provincialización de las dos Universidades en contradicción con el carácter regional proclamado por el art. 1 de la misma Ley, y lesiona la autonomia universitaria, en sus manifestaciones de libertad de creación en todo su ámbito territorial de estructuras específicas que actúen como soporte de la investigación y la docencia (3.2.g LRU), y de potestad de autonormación (3.2.a LRU), al tener que modificar sus Estatutos por razones de oportunidad politica.

- EI TC señala que la contradicción que pueda existir entre el art. 4 y el carácter regional que el atr. 1.2 de la misma Ley reconoce a las dos Universidades Canarias carece de trascendencia constitucional, puesto que este art. 1.2, no puede servir de contraste de constitucionalidad de otra norma legal, venga o no incluida en la misma Ley, sin que, por otro lado, la Constitución o la LRU conten- 
gan precepto alguno que establezca que la autonomía universitaria garantiza a las universidades un ámbito regional de actuación. Ademas el carácter regional de las Universidades Canarias no es totalmente negado en el art. 4 de la Ley, en cuanto permite, aunque sea de manera condicionada, que cada una de esas Universidades pueda tener centros en cada una de las islas del archipiélago Canario.

- Respecto a la facultad reconocida por las Universidades por el art. 3.2.g LRU, el TC señala que en nada se ve afectada o desconocida por el art. 4 de la Ley canaria, puesto que esa potestad organizativa de las Universidades no incluye la creación de centros o estructuras básicas encargadas de la organización de las enseñanzas universitarias encaminadas a la obtención de títulos académicos y su gestión administrativa, y son estas estructuras, justamente, a las que se refiere el art. 4 de la Ley canaria.

- Por lo que se refiere a la posible invasión de la potestad de autonormación conferida a las Universidades por el art. 3.2. a LRU, en cuanto obliga a modificar los Estatutos por razones de oportunidad política, el TC entiende que no se produce tal invasión, y lo explica en estos términos: "Es indudable que una reorganización universitaria, tan importante como es la cometida por la Ley canaria 5/1989, produce la necesidad inevitable de que las Universidades Canarias vengan obligadas a readaptar sus Estatutos y normas de funcionamiento interno a la nueva organización creada por la reforma; sin embargo, ello no entraña limitación alguna de la potestad estatutaria de dichas Universidades, siempre que la Ley que las reorganiza no les impida ejercitarla, decidiendo libremente cada una de ellas sobre dicha readaptación, aunque les imponga un plazo para llevar a efecto con subrogación gubernativa en caso de incumplimiento, puesto que esta limitación temporal, justificada por exigencias elementales de seguridad jurídica, es una cautela razonable que tiene por objeto evitar que la omisión voluntaria de la Universidad en el ejercicio de su competencia conduzca a una anomalía incompatible con el correcto funcionamiento de la institución universitaria.

4) Composición de los Claustros.

- La readscripción de centros y el consiguiente trasvase de Profesores, personal de administración y servicios y alumnos de una a otra Universidad repercute en la composición de los Claustros existentes, en el momento de la readscripción, en cada una de las Universidades Canarias, pero si bien esa integración recíproca de 
los centros origina la necesidad de adecuar los Claustros existentes a la nueva situación, no se priva a las Universidades de llevar a cabo tal adecuación dentro del marco legal de las competencias que la LRU les atribuye, puesto que no se establece interferencia o condicionamiento alguno que permita apreciar invasión o vulneración de la autonomia universitaria que salvaguardan dichas competencias, las cuales podrán ser ejercitadas, sin que se imada a la Universidad de la Laguna reajustar su Claustro dentro de la proporcionalidad legalmente establecida y por el sistema democrático que tenga previsto su Estatuto.

FALLO: Declarar que los arts. 2 y 4 , y las Disposiciones adicional y transitoria de la Ley canaria impugnada, no se oponen a lo dispuesto en el art. 27.10 de la Constitución.

SENT. № 107/1990, DE 6 De JUNIO. SALA SEGUNDA.

RECURSO DE AMPARO ELECTORAL 1393/90. FRANCISCO RUBIO LLORENTE.

OBJETO: Interpuesto contra las resoluciones de las Juntas Electorales Provinciales de Almeria , Granada y Jaén, que denegaron la proclamación de las respectivas candidaturas del Partido "Unidad Centrista Andaluza. Partido Español Demócrata"(UCA-PED) a las elecciones al Parlamento andaluz, debido a uno ostentar los candidatos que las integran vecindad administrativa en Andalucia, y contra las Sentencias del Tribunal Superior de Justicia de Andalucía que confirmaron dichas resoluciones.

MATERIA: Exigencia de vecindad administrativa en Andalucía para ser candidato a la Cámara autonómica.

- La Ley Electoral de Andalucía 1/1986, exige a los candidatos a la Cámara autonómica la condición política de andaluces, manifestada en la vecindad administrativa en dicha C.A.

- Frente a tal requisito, ningún fundamento tiene la alegación del partido recurrente de que dicho requisito no viene contemplado por la Ley Orgánica del Régimen Electoral General, puesto que si bien las condiciones básicas que determinan la elegilidad activa $y$ pasiva vienen ya previstas en la legislación electoral general, la C.a, de Andalucia, en ejercicio de la competencia contemplada en el art. 13.5 de su Estatuto de Autonomía, puede legislar sobre las normas electorales para la constitución de sus instituciones de autogobierno. 
- Por lo tanto, al haberse rechazado la proclamación de las candidaturas del partido recurrente en aplicación razonable de una causa legal, no se ha impedido de forma indebida a los integrantes de las mismas el acceso a los cargos públicos en condiciones de igualdad que garantiza el art. 23.2 de la C.E.

FALLO: Desestimar el recurso de amparo.

OBSERVACION: La Sentencia no 109/1990, de 7 de junio, de la Sala Segunda del Tribunal Constitucional, cuyo Magistrado Ponente es D. Eugenio Diaz Eimil, que resuelve el recurso de amparo electoral $n^{\circ}$ 1407/90 interpuesto por el partido UCA-PED contra el Acuerdo de la Junta Electoral Provincial de Málaga, confirmada posteriormente por el Tribunal Superior de Justicia de Andalucia, que denegó la proclamación de la candidatura de dicho partido, tiene idéntico fundamento y fallo que la Sentencia del Tribunal Constitucional $n^{\circ}$ $107 / 1990$.

SENT. № 110/1990, DE 18 DE JUNIO. SALA SEGUNDA.

RECURSO DE AMPARO № 1463/87.

JOSE LUIS DE LOS MOZOS Y DE LOS MOZOS.

OBJETO: Interpuesto contra los Acuerdos de la Sala de lo Penal de la Audiencia Provincial de las Palmas de 21 y 22 de enero de 1987, relativos a la responsabilidad disciplinaria del MagistradoJuez recurrente en amparo. Contra dichos Acuerdos, el ahora solicitante de amparo interpuso recurso contencioso -administrativo ante la Sala correspondiente de la Audiencia Territorial de Las Palmas, con arreglo al procedimiento establecido en la Ley $62 / 1978$ invocando la lesión de los derechos reconocidos en los arts. 24.1 CE por indefensión y 25.1 CE, si bien, dicha Sala, por Sentencia de 7 de abril de 1987 declaró la inadmisibilidad del recurso planteado por entender que, siendo los Acuerdos sancionadores recurridos "actos de carácter jurisdiccional", la jurisdicción contencioso-administrativa no puede conocer de los mismos, siendo posible la revisión de los actos de otros órganos jurisdiccionales a través del recurso de amparo ante el Tribunal Constitucional. Interpuesto recurso de apelación, la Sala Quinta del Tribunal Supremo, por Sentencia de 21 de septiembre de 1987, desestimó el recurso.Finalmente, formalizo demanda de amparo en la que se alega vulneración de los derechos reconocidos en los arts. 24.1 y 25.1 de la CE. 
FALLO: Desestimar el recurso de amparo, puesto que, por un lado, no se vulnera el artículo 24.1 CE, ya que las sanciones impuestas no producen indefensión en cuanto tuvo oportunidad de defenderse, y la Sentencia de instancia, que declaró la inadmisibilidad del recurso contencioso-administrativo y que más tarde fue confirmada por la Sentencia de la Sala Quinta del T.S. dictada en apelación, adoptó una resolución motivada de inadmisión; $y$, por otro lado, no hay vulneración del artículo 25.1 CE puesto que las llamadas correcciones disciplinarias procesales están en vigor y no han sido derogadas por la Ley Orgánica del Poder Judicial 6/1985, de 1 de julio.

SENT. № 112/1990, De 18 DE JUNIO. SALA SEGUNDA.

RECURSO DE AMPARO № 61561988. ALVARO RODRIGUEZ BERREIJO.

OBJETO: Interpuesto contra el Auto de 22 de febrero de 1998 de la Audiencia Provincial de Palencia, confirmado en súplica por el de 11 de marzo de 1988, sobre liquidación de condena a pena de suspensión para el ejercicio de cargo público. Pretende el actor, funcionario público condenado por delito continuado de cohecho a pena de tres años de suspensión en el ejercicio de cargo público, que se compute para la liquidación de su condena el tiempo en que permaneció suspendido provisionalmente en sus funciones por orden de la autoridad administrativa, y que a tal efecto se declare la nulidad de las Resoluciones de la Audiencia Provincial de Palencia que le denegaron dicha pretensión. Basa su demanda de amparo en que las citadas Resoluciones infringieron el principio non bis in idem, implícitamente contenido en el art. 25.1 CE, así como el principio de igualdad garantizado en el art. 14 CE puesto que considera que, de no atenderse su petición, resultaría discriminado en comparación con quienes, condenados a pena de privación de libertad,les es abonado el periodo de prisión provisional, asi como respecto a quienes se les abona el cumplimiento de una sanción administrativa provisional cuando se les impone la sanción disciplinaria de forma definitiva.

FALLO: Denegar el amparo solicitado. Por un lado porque las situaciones presentadas por el actor como términos de comparación son completamente distintas, y no puede reputarse discriminatorio que el legislador las regule de forma diferente; mientras que en los supuestos comparativos planteados por el recurrente se trata del 
abono del cumplimiento preventivo o provisional respecto de sanciones firmes del mismo orden (penal en un caso, administrativo en otro), sin embargo, la pretensión formulada por el actor es que se le abone una suspensión provisional ordenada por la autoridad administrativa a una sanción penal firme. Por otro lado, el actor ha interpuesto el recurso de amparo antes de que hubiese concluido el expediente disciplinario, por lo que al no haber recaído sanción administrativa firme, no puede hablarse de duplicidad de sanciones; $y$ además, el hecho de no haber agotado los remedios judiciales ordinarios que estaban a su disposición conducen a la desestimación del recurso.

SENT. № 117/1990, DE 21 DE JUNIO. SALA PRIMERA. RECURSO DE AMPARO № 424/88. JESUS LEGUINA VILLA.

OBJETO: Interpuesto contra la Sentencia de la Sala Tercera del Tribunal Supremo, de 30 de noviembre de 1987, que revoca en apelación la dictada por la Sala Primera de la Audiencia Territorial de Valencia, en recurso contencioso-administrativo sobre liquidaciones municipales del Impuesto sobre el Incremento del Valor de los Terrenos. Se queja la demandante de que la Sentencia impugnada fue dictada inaudita parte $y$, por tanto, sin que se le ofreciera la posibilidad de ejercer su derecho de defensa y contradecir las argumentaciones de la parte apelante, lo que condujo a que fuera revocada la Sentencia apelada (que era favorable a sus pretensiones) y a una inconstitucional situación material de indefensión, lesiva del art. 24.1 Ce. Todo ello fue la consecuencia de un error de la Audiencia Territorial de Valencia que, mediante providencia de 7 de noviembre de 1986, emplazó a la demandante a que compareciera ante la Sala Cuarta del Tribunal Supremo, en lugar de hacerlo, como correspondía, ante la Sala Tercera, que era la realmente competente para conocer del recurso por razón de la materia, circunstancia ésta de la que la demandante no tuvo conocimiento hasta que, por providencia de 23 de febrero de 1988, la citada Sala Tercera le devolvió el escrito de personación y le notificó que ya se había dictado Sentencia con fecha de 30 de noviembre de 1987.

FALLO: Estimar el recurso de amparo, puesto que los errores de los órganos judiciales no deben producir efectos negativos en la esfera juridica del justiciable, salvo en los casos en que la situación acaecida sea también imputable a la falta de diligencia de la parte. 
En su virtud, corresponde:

10 Anular la Sentencia impugnada.

$2^{\circ}$ Reconocer el derecho de la recurrente en amparo a obtener la tutela judicial efectiva.

3o Restablecer a la recurrente en la integridad de su derecho vulnerado para lo cual deberán retrotraerse las actuaciones seguidas en el rollo de apelación antes citado al momento inmediatamente posterior a la presentación del escrito de personación, con la finalidad de que sea oportunamente personación, con la finalidad de que sea oportunamente proveido tal escrito y de que la recurrente pueda comparecer y actuar como parte apelada ante la Sala del TS que corresponda.

SENT. № 119/1990, DE 21 DE JUNIO. PLENO. RECURSO DE AMPARO № 507/90. FRANCISCO RUBIO LLORENTE.

OBJETO: Promovido contra la decisión del Presidente del Congreso de los Diputados de 4 de diciembre de 1989, por la que se deniega a los recurrentes la adquisición de la condición plena de Diputados al no haber utilizado la fórmula reglamentaria para prestar juramento o promesa de acatamiento a la Constitución, por haber antepuesto la expresión "por imperativo legal". Los derechos fundamentales que los recurrentes aducen en apoyo de su petición son los que nuestra Constitución garantiza en sus arts. 14 y 23.2.

FALLO: Otorgar el amparo, puesto que al considerar que la adición de la citada expresión implicaba el imcumplimiento del requisito impuesto por el art. 20 del Reglamento del Congreso de los Diputados, la interpretación que de este precepto ha hecho el Presidente de la Cámara es lesiva del derecho de los recurrentes a acceder a la condición de Diputados "en condiciones de igualdad, con los requisitos que señalan las leyes" porque incluye entre tales requisitos una prohibición que no figura en las leyes mismas. En consecuencia, corresponde:

1 - Anular el Acuerdo impugnado de 4 de diciembre de 1989.

2o Reconocer el derecho de los recurrentes a acceder, en condiciones de igualdad, a la función de Diputados, con los requisitos que señalan las leyes.

3o Restablecerlos en ese derecho, declarando que han adquirido la condición plena de Diputados mediante la prestación de la promesa de acatamiento a la Constitución con el empleo de la fórmula por ellos utilizada. 
SENT. № 120/1990, DE 27 DE JUNIO.PLENO.

RECURSO DE AMPARO № 443/1990. FERNANDO GARCIA-MON $Y$ GONZALEZ-REGUERAL, EUGENIO DIAZ EIMIL Y JOSE VICENTE GIMENO SENDRA.

OBJETO: Interpuesto contra el Auto de la Sección Segunda de la Audiencia Provincial de Madrid de 15 de febrero de 1990, que resuelve el recurso de apelación contra la providencia dictada por el Juzgado de Vigilancia Penitenciaria $n^{\circ} 2$ de Madrid, de 5 de enero de 1990 , sobre asistencia médica a reclusos en huelga de hambre. Se trata de determinar la compatibilidad con los arts. 1.1,9.2, 10.1, $15,16.1,17.1,18.1,24.1$ y 25.2 Cede la resolución judicial que, ante la negativa a ingerir alimentos, manifestada por los internos recurrentes en reivindicación de la concentración en un mismo establecimiento penitenciario de los recursos pertenecientes a los GRAPO, autoriza y obliga a la Administración penitenciaria a prestar asistencia médica, en cuanto ello implique la alimentación de los internos en contra de su voluntad. La resolución judicial impugnada declara "el derecho-deber de la Administración penitenciaria de suministrar asistencia médica, conforme a los criterios de la ciencia médica, a aquellos reclusos en huelga de hambre una vez que la vida de éstos corra peligro, lo que se determinará, previos los oportunos informes médicos, en la forma que el Juez de Vigilancia Penitenciaria correspondiente determine, y sin que en ningún caso pueda suministrarse la alimentación por vía bucal en tanto persista su estado de determinarse libre y conscientemente".

FALLO: Denegar el amparo solicitado puesto que "la asistencia médica obligatoria autorizada por la resolución judicial objeto del recurso de amparo no vulnera ninguno de los derechos fundamentales invocados por los demandantes, ni en si misma, ni en la forma y alcance con que ha sido autorizada, constituyendo tan solo una limitación del derecho a la integridad física y moral garantizada por el art. 15 de la Constitución, y unida ineludiblemente a ella una restricción a la libertad física, que vienen justificadas en la necesidad de preservar el bien de la vida humana, constitucionalmente protegido, y que se realiza mediante un ponderado juicio de proporcionalidad, en cuanto entraña el mínimo sacrificio del derecho que exige la situación en que se hallan aquéllos respecto de los cuales se autoriza". 
VOTOS PARTICULARES: Formulados por D. Miguel Rodriguez-Piñero y Bravo-Ferrer, y por D. Jesús Leguina Villa.

SENT. № 122/1990, DE 2 DE JULIO. SALA SEGUNDA. RECURSO DE AMPARO № 643/1988.

JOSE LUIS DE LOS MOZOS Y DE LOS MOZOS.

OBJETO: Interpuesto contra la Sentencia de la Sala Quinta del Tribunal Supremo de 8 de febrero de 1988, desestimatoria del recurso de apelación contra la Sentencia de la Sala Cuarta de lo Contencioso-Administrativode la Audiencia Territorial de Madrid de 16 de septiembre de 1986, que confirmó la adecuación a Derecho del Acuerdo del Presidente de la Comunidad de Madrid de 18 de junio de 1985, por el que se fijaron los servicios mínimos en los Centros asistenciales dependientes de la referida Comunidad con motivo de la huelga convocada por la Confederación Sindical de Comisiones Obreras para el día 20 de junio de 1985. Supuesta vulneración del derecho de huelga (art. 28.2 CE).

\section{MATERIAS:}

1) Competencia del Presidente de la C.A. de Madrid para acordar los servicios mínimos de los centros afectados.

- A juicio de los demandantes de amparo el Presidente de la C.A. de Madrid sería incompetente para acordar los servicios mínimos de los Centros (Residencias de Ancianos, de titularidad de la C.A.) afectados por la convocatoria de huelga, y ello por estimar que, como regla, la competencia será de la "Autoridad gubernativa", sin que el Presidente de la C.A. de Madrid, a los efectos de fijar los servicios mínimos en los centros de huelga, pueda actuar como tal; conclusión ésta -se añade- que aún debe mantenerse con mayor rigurosidad cuando los centros o servicios de que se trate no hayan sido transferidos a la C.A.

- Pero el T.C. entiende que en el presente caso resulta evidente que no excedía del ámbito competencial de la C.A. de Madrid, y de sus órganos de gobierno la toma de decisión en orden a determinar y fijar los servicios mínimos a observar en las Residencias de Ancianos afectadas por la convocatoria de la huelga, dado que tales residencias no han sido transferidas por depender ya con anterioridad de la Diputación Provincial de Madrid, primero, y mas tarde, de la propia C.A. 
2) Motivación de la decisión imponiendo servicios mínimos, así como la intensidad y alcance de los mismos.

- Para los recurrentes, la vulneración del derecho de huelga se evidencia, asimismo, en la falta de motivación de la decisión adoptada imponiendo dichos servicios, así como en la intensidad y alcance de los mismos, que han vaciado de contenido el ejercicio del derecho de huelga.

- Pero el T.C. entiende que, si bien es cierto que la omisión de la garantía consistente en la precisa motivación supone una vulneración del derecho reconocido en el art. 28.2 CE, sin embargo en este caso no hubo tal falta de motivación puesto que existe una amplia justificación de las razones determinantes de los servicios que se habian de considerar esenciales de los bienes afectados (la vida y salud de los ancianos) y en función de ello el número de trabajadores que quedaron afectados por la fijación de servicios mínimos; $y$ lo mismo hay que decir del contenido y alcance de los servicios mínimos impuestos, pues existe una "razonable proporción" entre los sacrificios que se imponen a los huelguistas y los que padecen los usuarios.

FALLO: Denegar el amparo solicitado.

SENT. № 125/1990, DE 5 DE JULIO. SALA PRIMERA.

RECURSO DE AMPARO № 138/1988. LUIS LOPEZ GUERRA.

OBJETO: Interpuesto contra la Resolución de la Mesa del Parlamento de Canarias, de 8 de octubre de 1987, que resuelve no modificar unos acuerdos de fechas 20 y 21 de julio de 19887, por los que se deniega la formación de un Grupo Parlamentario.

FALLO: Denegar el amparo solicitado por concurrir el motivo de inadmisión consistente en el ejercicio en el ejercicio de la acción de amparo fuera de plazo (art. 50.1.a, en relación con el art. 42 de la LOTC). En el presente caso, los acuerdos de la Mesa del Parlamento de Canarias, de 20 y 21 de julio de 1987, debieron estimarse como firmes y procedía acudir directamente en amparo ante el tribunal Constitucional, puesto que ni era reglamentariamente posible intentar una solicitud de reconsideración de estos acuerdos ni, menos aún, cabía la interposición de un recurso contencioso-administrativo por la vía de la Ley 62/1978 contra un acto parlamentario que no afectaba a cuestiones relacionadas con el personal de las Cámaras, de acuerdo con el art.74.1.c) de la LOPJ. 
SENT. № 131/1990, DE 16 DE JULIO. SALA PRIMERA.

RECURSO DE AMPARO № 732/1990. LUIS LOPEZ GUERRA.

OBJETO: Interpuesto por un representante de las candidaturas por Avila del Partido Popular en las elecciones a Cortes Generales de 29 de octubre de 1989, contra la Sentencia de la Sala de lo Contencioso-Administrativo del Tribunal Superior de Justicia de Castilla y León, con sede en Burgos, de 28 de febrero de 1990, que declara la invalidez del acta de la votación en la localidad de Mamblas al llegar a la conclusión de que dicho acta "no fue fiel reflejo del resultado de la votación". Entiende el recurrente en amparo que se han conculcado los derechos reconocidos en los arts. 24.1 y $23 \mathrm{CE}$.

FALLO: Otorgar parcialmente el amparo puesto que la anulación del acta de Mamblas priva al recurrente en amparo de un número de votos que suponían la atribución del escaño de Senador; y al no haber hecho la Sala esta comprobación de relevancia y no haber, en consecuencia, ordenado efectuar nueva convocatoria de elecciones en la localidad de Mamblas, se ha vulnerado el derecho del recurrente a ceder al cargo en términos de igualdad, puesto que se le ha privado de unos votos que podrían significar su proclamación como Senador electo. Ha significado, asimismo, vulnerar el derecho a la participación en los asuntos públicos de los electores de Mamblas, que se han visto privados de su voto en un supuesto no contemplado por la Ley Electoral, cuando dicho voto era relevante para el resultado de la elección. Por consiguiente, corresponde:

10 Anular en parte la Sentencia impugnada, en lo relativo a la proclamación como candidato electo para el Senado del candidato del CDS.

$2^{\text {- }} \quad$ Acordar la celebración de nueva votación para el Senado en la Mesa de Mamblas, dentro del plazo establecido en el art. 113.d), de la L.O.R.E.G.

3o Acordar que, celebrada dicha votación, se integren los resultados en los generales de la circunscripción en los términos expresados en el fundamento jurídico $7^{\circ}$.

SENT. № 132/1990, DE 17 DE JULIO. PLENO.

CUESTION DE INCONSTITUCIONALIDAD № 945/1990. VICENTE GIMENO SENDRA.

El objeto y fallo de esta Sentencia es idéntico al resuelto por la Sentencia del T.C. no 106/1990, de 6 de junio (BOE de 5 de julio), relativa a 
la posible incompatibilidad con la autonomía universitaria de algunos preceptos de la Ley canaria 5/1989, de 4 de mayo, de Reorganización Universitaria de Canarias.

SENT. № 133/1990, DE 19 DE JULIO. PLENO.

RECURSO DE INCONSTITUCIONALIDAD № 355/1985, Y CONFLICTO POSITIVO DE COMPETENCIA ACUMULADO AL RECURSO ANTERIOR № 1694/1989. LUIS LOPEZ GUERRA.

OBJETO: El recurso de inconstitucionalidad es promovido por el Gobierno Vasco, contra la Ley 2/1985, de 21 de enero, sobre Protección Civil; y el conflicto positivo de competencia, acumulado al recurso anterior, también es promovido por el Gobierno Vasco frente a determinados anexos de la Orden de 29 de marzo de 1989, por la que se dispone la publicación del Acuerdo del Consejo de Ministros de 3 de marzo de 1989, que aprueba el Plan Básico de Emergencia Nuclear.

MATERIAS:

1) Concurrencia de competencias en materia de protección civil.

- Por la misma naturaleza de la protección civil, que persigue la preservación de personas y bienes en situaciones de emergencia, se produce en esta materia un encuentro o concurrencia de muy diversas Administraciones Públicas (de indole o alcance municipal, supramunicipal o insular, provincial, autonómica, estatal) que deben aportar sus respectivos recursos y servicios. Desde esta perspectiva, y en principio, la competencia en materia de protección civil dependerá de la naturaleza de la situación de emergencia, y de los recursos y servicios a movilizar. Ello puede suponer, de acuerdo con los términos de los respectivos Estatutos, que la Administración Autonómica sea competente en esta materia.

2) Límites de la competencia autonómica derivados de intereses nacionales o supraautonómicos.

- La competencia autonómica se encuentra con determinados límites, que derivan de la existencia de un posible interés nacional o supraautonómico que pueda verse afectado por la situación de catástrofe o emergencia: Bien por la necesidad de prever la coordinación de Administraciones diversas, bien por el alcance del evento (afectando a varias Comunidades Autónomas) o bien por sus dimensiones, que pueden requerir una dirección nacional de todas 
las Administraciones públicas afectadas, y una aportación de recursos de nivel supraautonómico. $Y$, como consecuencia, e intimamente en relación con tal posibilidad, no pueden negarse al Estado las potestades necesarias para obtener y salvaguardar una coordinación de distintos servicios y recursos pertenecientes a múltiples sujetos, asi como (si fuera necesario) para garantizar una dirección y organización unitarias: Esto es, tanto competencias de tipo normativo (disponiendo e instrumentando técnicas de coordinación) como de tipo ejecutivo, asumiendo las instancias estatales tareas de dirección. Las competencias asumidas por las Comunidades Autónomas encuentran pues, su límite, en la política de seguridad pública que la Constitución reserva a la competencia estatal en su art. 149.1.29, en cuanto tal seguridad pública presenta una dimensión nacional, por la importancia de la emergencia, o por la necesidad de una coordinación que haga emergencia, o por la necesidad de una coordinación que haga posible prevenir y, en su caso, reducir los efectos de posibles catástrofes o emergencias de alcance supraautonómico.

- La propia Ley impugnada, parece asumir esta posición a tenor de su Exposición de Motivos, que en su apartado I identifica la protección civil como "protección física de las personas y de los bienes en situación de grave riesgo colectivo, calamidad pública o catástrofe extraordinaria en la que la seguridad y la vida de las personas pueda peligrar y sucumbir masivamente". Y la regulación legal viene a orientarse al estudio, prevención y protección de situaciones de excepcionalidad o grave riesgo, distintos de situaciones de emergencia con carácter cotidiano, en que se manifiesta un interés nacional.

3) Materias concretas de la Ley de Protección Civil que se impugnan.

Se comprueba si los distintos preceptos de la Ley se corresponden con este planteamiento genérico, o si vulneran las competencias al respecto de la C.A. del País Vasco: Si así fuera, ello traería como consecuencia, no I a nulidad de los preceptos impugnados (que, dada la diversidad de regímenes competenciales, pudieran ser de aplicación en otras Comunidades Autónomas) sino su inaplicabilidad al Pais Vasco.

Las impugnaciones que se hacen se refieren a las siguientes materias:

- Competencia sobre la Protección Civil (arts.1.2 y 2.1).

- Competencias del Gobierno para: establecer un catálogo de las actividades de todo orden que pueden dar origen a situaciones de 
emergencia (art. 5); emanar unas directrices básicas que regulen la protección civil, a propuesta del Ministerio del Interior y previo informe de la Comisión Nacional de Protección Civil (art. 6.1, párrafo 2ª); y concertar acuerdos con la Cruz Roja por medio de sus Ministros de Interior y de Defensa (art.7.2).

- Actuación en casos de emergencia y planes de protección civil (capítulo III): Elaboración por el Gobierno de una Norma Básica de Protección Civil que determine las líneas de actuación en esta materia y contenga las directrices esenciales para la elaboración de los distintos Planes Territoriales y Especiales (art.8); fijación de un contenido mínimo e indisponible de los diferentes Planes Territoriales (art.9); establecimiento de las instancias correspondientes para la elaboración de los distintos Planes Territoriales, así como la necesidad de su homologación por la Comisión Nacional de Protección Civil (art.10); la potestad de recabar la información necesaria para la elaboración y ejecución de estos planes (art.12); e instancias que deberán disponer la aplicación del Plan que corresponda, la movilización de los servicios y medios necesarios (art.13).

- Actuaciones preventivas en materia de protección civil (capítuIo IV, artículo 14).

- Organización básica de la dirección y coordinación en esta materia (capítulo V): calificación del Gobierno como órgano superior de dirección y coordinación de la protección civil (art.15); potestades del Ministerio del Interior (art.16);composición de la Comisión Nacional de Protección Civil (art.17) y la análoga Comisión de ámbito de la C.A. (art.18).

- Infracciones a esta normativa y sanciones (cap. VI, art.19).

- Atribución al Gobierno de potestades para elaborar un plan financiero incorporado a los Presupuestos Generales del Estado para hacer frente a las obligaciones que se deriven de la aplicación de esta Ley (disposición adicional).

- Normas de derecho transitorio (disposición transitoria).

- Imposición a la Administración autónoma de la obligación de revisar los reglamentos, normas y ordenanzas sobre seguridad de las empresas, edificaciones, industrias, servicios y medios de transporte colectivo para adecuar su contenido a la presente ley y a las disposiciones que la desarrollen (D.F.1하).

- Creación por el Gobierno de una Red de Alarma Nacional dependiente de los órganos de protección civil del Estado y coordinada con los correspondientes del Ministerio de Defensa, para alertar a la población en casos de emergencia (D.F. 3ª). 
4) Conflicto de competencia frente a la Orden que dispone la publicación del Plan Básico de Emergencia Nuclear.

- Resultan aplicables al Plan Básico de Emergencia Nuclear las consideraciones efectuadas en la propia Sentencia en relación con la reserva a la competencia estatal que resulta del art. 149.1.29 CE, para la actuación en materia de protección civil cuando la extensión o intensidad de la catástrofe superase el ámbito de una Comunidad Autónoma.

- Cuestiones competenciales concretas: Integración en el Plan de órganos, autoridades o servicios de la C.A.; previsiones sobre servicios municipales y provinciales sin tener en cuenta la efectiva distribución de competencias en materia de protección civil; y no referencia a la intervención de la Junta de Seguridad del País Vasco.

\section{FALLO:}

1. Estimar parcialmente el recurso de inconstitucionalidad, $y$, en su virtud, declarar que el inciso "deberán ser aprobados por el Consejo de Gobierno de la misma" del art. 10.1, párrafo tercero, sólo será aplicable supletoriamente a la C.A. del País Vasco, en defecto de norma autonómica, en los términos del fundamento jurídico 10 ,

2. Desestimar el recurso en todo lo demás.

3. Desestimar en su totalidad el conflicto de competencia, declarando que pertenece al Estado la competencia controvertida.

VOTO PARTICULAR: Formulado por D. LUIS LOPEZ GUERRA.

SENT. № 137/1990, DE 19 DE JULIO. PLENO.

RECURSO DE AMPARO № 397/1990. JESUS LEGUINA VILLA, JOSE LUIS DE LOS MOZOS Y DE LOS MOZOS Y VICENTE GIMENO SENDRA.

La fundamentación y el fallo de esta sentencia (resolutoria del recurso interpuesto contra Autos de la Audiencia Provincial de Guadalajara que resuelven los recursos de apelación y súplica frente al Auto dictado por el Juzgado de Vigilancia Penitenciaria de Guadalajara sobre asistencia médica a reclusos en huelga de hambre), son idénticos a los emitidos en la Sentencia del Pleno del Tribunal Constitucional $n^{\circ}$ 120/1190, de 27 de junio ( $B O E$ de 30 de julio), dictada en relación con el recurso de amparo 443/1990.

VOTO PARTICULAR : Formulado por D. Jesús Leguina Villa. 
